http://portaldeperiodicos.unisul.br/index.php/EeN/index

\title{
AVALIAÇÃO DA PERSONALIDADE DA MARCA PAGUE MENOS NA ÓTICA DOS CLIENTES ${ }^{1}$ PAGUE MENOS BRAND PERSONALITY EVALUATION UNDER CUSTOMERS VIEW EVALUACIÓN DE PERSONALIDAD DE LA MARCA PAGUE MENOS EN LA ÓPTICA DE LOS \\ CLIENTES
}

\author{
André Luiz Maranhão de Souza Leão \\ Doutorado em Administração pela Universidade Federal de Pernambuco (UFPE) \\ Professor adjunto do Departamento de Ciências Administrativas (DCA/UFPE) \\ Endereço: DCA / UFPE, s/n, Cidade Universitária, CEP 51130-010. Recife, Brasil - PE \\ Telefone: (81) 2126-8368. E-mail: aleao21@hotmail.com
}

\section{Thiago lanatoni Camargo}

Mestre em Administração pelo Programa de Pós-Graduação em Administração (PROPAD / UFPE) Coordenador dos cursos de Comunicação Social e Tecnológico em Fotografia na Uninassau-PE Endereço: UFPE / PROPAD, Av. Prof. Moraes Rego, 1235, CEP 50670-901. Recife, Brasil - PE E-mail: ianatoni@gmail.com

\section{Rodrigo César Tavares Cavalcanti}

Mestrando em administração na Universidade Federal de Pernambuco (UFPE)

Endereço: DCA / UFPE, s/n, Cidade Universitária, CEP 51130-010. Recife, Brasil - PE

Telefone: (81) 2126-8368. E-mail: rodrigoctc@gmail.com

\section{Sérgio Luiz Elias de Araújo}

Doutor em Administração pela Universidade Federal de Pernambuco (UFPE)

Professor efetivo da Universidade Federal de Sergipe

Endereço: UFPE / PROPAD, Av. Prof. Moraes Rego, 1235, CEP 50670-901. Recife, Brasil - PE

Telefone: (79) 9961-0181. E-mail: sergioaraujo@sergioaraujo.com.br

\section{Carlos Eduardo Polônio da Silva}

Mestre em Administração no PROPAD / UFPE

Professor na Faculdade dos Guararapes, FG, Brasil

Endereço: UFPE / PROPAD, Av. Prof. Moraes Rego, 1235, CEP 50670-901. Recife, Brasil - PE

E-mail: caepolonio@gmail.com

Artigo recebido em 04/09/2014. Revisado por pares em 25/11/2014. Reformulado em 10/12/2014. Recomendado para publicação em 20/12/2014 por Ademar Dutra (Editor Científico). Publicado em 30/12/2014. Avaliado pelo Sistema double blind review.

\footnotetext{
${ }^{1}$ A realização deste trabalho só foi possível graças ao apoio do Conselho Nacional de Desenvolvimento Científico e Tecnológico (CNPq), que fomentou, por meio de custeio e bolsa, a pesquisa que deu origem a este artigo.
}
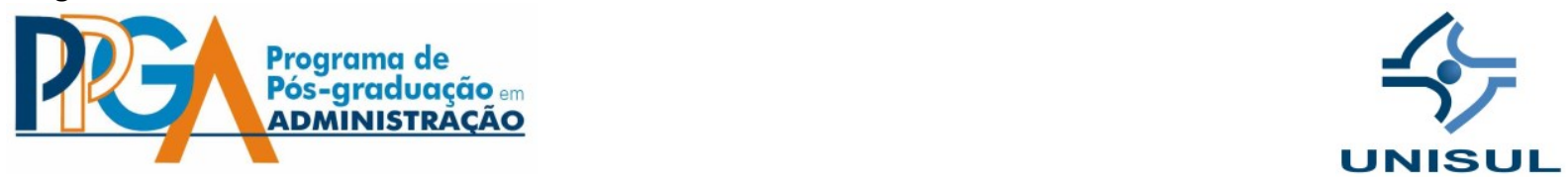


\section{RESUMO}

Existe uma crescente busca das organizações em criar relacionamentos com seus consumidores por meio de suas marcas, e a noção de personalidade de marca tem uma função primordial no estabelecimento desse vínculo. Com base nisto, debruçamo-nos sobre a Pague Menos, maior rede varejista farmacêutica do Brasil, com o objetivo de identificar e avaliar as características humanas que a compõem, sob a ótica de seus clientes. Para tal, realizamos o presente estudo qualitativo, executado por meio de entrevistas em profundidade, submetidas a uma análise de discurso funcional. Nossos resultados revelam oito características (acessível, atenciosa, diversificada, magnânima, midiática, prodigiosa, providente e relapsa) que compõem a personalidade da marca Pague Menos e que, em sua interseção mais ampla, propiciou descrevê-la como provedora.

Palavras-chave: Marketing; Branding; Personalidade de Marca; Marca de Varejo.

\section{ABSTRACT}

There is a growing search by organizations in building relationships with their customers through their brands, and the concept the brand personality plays a major role in the stablishment of this bond. Based on this, we focused on Pague Menos, the largest pharmaceutical retailer in Brazil, with the aim of identifying and evaluating the human characteristics that compose it from its customers' perspective. Thereunto, we undergone present qualitative study through in-depth interviews, and submitted to a functional discourse analysis. Our results reveal eight characteristics (accessible, caring, diverse, magnanimous, mediating, prodigious, provident and sloppy), which compose Pague Menos brand personality, and in its broader intersection, enabled us to describe it as provider.

Keywords: Marketing; Branding; Brand Personality; Retail Brand.

\section{RESUMEN}

Existe una creciente búsqueda de las organizaciones en crear relacionamientos con sus consumidores por medio de sus marcas, y la noción de personalidad de marca tiene una función primordial en el establecimiento de ese vínculo. Con base en eso, direccionamos sobre la Pague Menos, mayor rede de venta al por menor farmacéutica de Brasil, con el objetivo de identificar y evaluar características humanas que la componen, bajo la óptica de sus clientes. Para eso fue realizado este estudio cualitativo por medio de entrevistas en profundidad, sometidas a un análisis de discurso funcional. Nuestros resultados revelan ocho características (accesible, atenta, diversa, magnánima, mediática, prodigiosa, providente y laxa) que componen la personalidad de la marca Pague Menos, y que en su intersección más amplia, nos propició describirla como proveedora.

Palabras-clave: Marketing; Branding; Personalidad de Marca; Marca de Venta al por Menor. 


\section{INTRODUÇÃO}

As organizações têm promovido esforços contínuos e exaustivos no gerenciamento das imagens atribuídas as suas marcas, buscando alcançar um alinhamento entre suas pretensões e as do mercado em que atuam, visto que estas, hoje, são protagonistas como critério de escolha dos consumidores (KELLER, 2011; SONNIER; AINSLE, 2011; ROCHA et al., 2009; GUERRERO, 2008). Respectivamente, percebemos a busca proeminente com a qual as organizações têm procurado estabelecer relacionamentos duradouros com os seus clientes, estabelecendo perspectivas mais relacionais em suas práticas de gestão (PALMATIER et al., 2011; PATSIOURA; MALAMA; VLACHOPOULOU, 2011). Entre gerir a imagem da marca e administrar os relacionamentos com os diferentes públicos, evidenciamos os estudos acerca dos relacionamentos entre marcas e consumidores (FOURNIER, 1998; SUNG; CHOI, 2010; PARÍS, 2011; SWAMINATHAN; PAGE; GÜRHAN-CANLI, 2007; VIEIRA, 2006), nos quais o conceito de personalidade de marca emerge como uma questão chave na compreensão acerca dessa relação.

A personalidade de marca compreende uma perspectiva antropomórfica sobre as marcas, assumindo que estas incorporam características humanas, como se fossem pessoas, a partir do modo como os indivíduos interagem com elas (AAKER, 1997; GROHMANN, 2009; MÄLAR et al., 2011).

Considerando o desenvolvimento contínuo da economia brasileira, parece-nos adequado que marcas genuinamente nacionais tornem-se cada vez mais relevantes, demandado, tanto da academia quanto de profissionais do mercado brasileiro, um esforço concentrado e crescente no sentido de produzir conhecimento sobre nossas marcas. Sobretudo, ao considerarmos que os estudos produzidos por nossa academia, especialmente os que se referem à questão da personalidade da marca, debruçam-se sobre marcas internacionais, principalmente de âmbito global, visando a reproduzir e adaptar trabalhos e escalas recorrentes em trabalhos estrangeiros, objetivando confirmar teorias estabelecidas e adaptando-as à nossa realidade.

A partir disto, debruçamo-nos sobre a Pague Menos, uma empresa destacada no âmbito nacional, com trinta anos de mercado. Ela aparece entre as empresas de maior crescimento contínuo do país, com taxa aproximada de $30 \%$ ao ano, segundo informações 
divulgadas em seu portal oficial ${ }^{2}$. A marca estabelece-se como maior rede de varejo farmacêutico, com mais de quatrocentas lojas, estabelecidas em todos os Estados brasileiros e contando com mais de treze mil funcionários.

Neste sentido, acreditamos que a adoção do conceito de personalidade de marca é uma escolha adequada para a análise da imagem de uma marca sob um prisma relacional. Assim, o presente estudo tem por objetivo identificar e avaliar as características humanas que compõem a personalidade da marca Pague Menos sob a ótica de seus clientes.

Para esta finalidade, todavia, não adotamos o conceito de personalidade de marca como um construto teórico, de forma a analisar suas variáveis, o que poderia ser feito por meio de mensuração e uso de escalas. Ao invés disto, orientamo-nos por uma postura de caráter indutivo, no intuito de capturar o ponto de vista dos consumidores de maneira mais espontânea, de forma a preservar como se expressam em relação à marca estudada.

Desta maneira, nosso propósito alinha-se a uma abordagem emergente no estudo das marcas, explorando uma perspectiva sociológica acerca da visão dos consumidores, também se alinhando a uma emergente agenda de pesquisa de abordagem interpretativista em marketing (MELLO, 2006; FARIA, 2006; MISOCZKY; AMANTINO-DE-ANDRADE, 2005; VIEIRA, 2002), que assume a realidade como uma construção sociocultural (BERGER; LUCKMANN, 2009; DENZIN; LINCOLN, 2005).

\section{PERSONALIDADE DE MARCA}

Nos dias atuais, uma marca significa, para os consumidores, bem mais que um nome ou símbolo que identifique e represente um produto, serviço ou organização. Ela configura um conjunto de valores e significados que expressam, tanto características funcionais, como emocionais atreladas a si (KAPFERER, 1998). Tal percepção representa um processo de evolução histórica. A marca deslocou-se de um elemento constituinte do produto, componente do marketing mix, para uma posição eminente sendo, por diferentes autores, apontada como uma evolução ao próprio marketing. Em um primeiro momento do marketing, a marca atendia ao papel de informar ao consumidor o produto, sua origem e procedência, tanto para sinalizar o produto no ponto de venda, como para garantir uma credibilidade quanto à procedência e qualidade, fornecendo segurança ao consumidor com

\footnotetext{
${ }^{2}$ http://portal.paguemenos.com.br/portal/empresa/historico Revista Eletrônica de Estratégia \& Negócios, Florianópolis, v.7, n.3, set./dez. 2014.
} 
relação às expectativas de benefício. Após a segunda grande guerra e diante de um crescimento econômico, empreendedor e tecnológico, a pluralidade de marcas ofertando bens semelhantes provoca um primeiro deslocamento deste papel das marcas sobre o composto de marketing (SEMPRINI, 2006).

Gestores de marketing precisavam distinguir seus produtos dos demais concorrentes. Surge o conceito de posicionamento, e as estratégias de construção de uma identidade particular a ser estabelecida como referência pelos consumidores. Incialmente, as estratégias de posicionamento adotaram argumentos funcionais para estabelecer tais distinções (SEMPRINI, 2006, RIES; 2002). Em um segundo momento, por volta dos anos de 1980, este posicionamento ganha novo rumo, em que estrategistas de marketing passam a adotar, como meio para posicionar e diferenciar suas marcas, o uso de elementos subjetivos, valores e sentimentos humanos (HOLT, 2002; GOBÉ, 2002). Sobre este processo, a marca alinha-se em importância aos demais elementos do composto de marketing, e passa a ganhar ênfase nas estratégias das organizações (SEMPRINI, 2006).

Contemporaneamente, gestores e acadêmicos atentos às mudanças de comportamento sociocultural, no qual o consumo se estabelece cada vez mais como eixo central das relações, as marcas passam a exercer mais que uma função de segurança na decisão de compra: elas assumem o papel de signo cultural, representam valores e significados almejados pelos consumidores como meio de representação daquilo que desejam demonstrar ser em suas interações sociais (LEÃO; MELLO; FREITAS, 2011; BROWN, 1994; COVA, 1997; LEE, 1993).

Com isto, a marca assume uma posição central às estratégias de marketing. 0 composto de marketing passa a compreender-se como elementos táticos à construção desta (SEMPRINI, 2006). Sob esta condição, os modelos propostos para a construção de marcas têm considerado todos os aspectos possíveis na interação com os consumidores, de modo a instituir sobre eles uma imagem que estabeleça uma identificação e, consequentemente, a lealdade deste destes para com a marca (AAKER, 1998).

Diante desta condição de busca por uma relação, um dos objetivos do branding apresenta-se na necessidade de construção de uma identidade para a marca, um conjunto de atributos e valores coerentes com a missão, visão e valores de uma organização. Tais condições são comunicadas para os consumidores por meio dos diversos elementos que 
manifestam a marca, evidenciam os valores culturais da marca, a relação dela com os consumidores, e exibem a marca e os próprios consumidores (AZOULAY; KAPFERER, 2003).

Em meio a esta interação, os valores subjetivos caracterizam uma personalidade a ser atribuída à identidade da marca. A esta personalidade, Azoulay e Kapferer (2003) compreendem constituir uma das principais facetas que compõem a identidade de uma marca. A personalidade de marca é um agrupamento de características humanas relacionadas a uma marca. Aaker (1997) elaborou uma escala própria para este construto, que é categorizado em cinco dimensões de traços de personalidade (sinceridade, excitação, competência, sofisticação e austeridade), as quais denominou de big five, e as subdividiu em quinze facetas. A partir desse estudo, a personalidade de marca ganhou força baseada em uma lógica dimensional do construto em diferentes variantes (GROHMANN, 2009; KIM, BAEK, T. H.; MARTIN, 2010; MADRIGAL; BOUSH, 2008).

Para Aaker (1996), estas qualidades são provenientes de diversas fontes relativas à marca, ou por estarem elas relacionadas aos seus produtos como categoria, atributos, embalagem, preço, ou por se relacionarem a outros aspectos pelos quais venha a se expressar, tais como estilo de comunicação, símbolos, endosso de celebridades ou imagem. Estes aspectos trabalham de forma a mediar a relação entre a marca e seus consumidores, visto que o conceito de relacionamento entre uma marca e uma pessoa pode ser comparado à relação entre duas pessoas; ou seja, podem ser apenas funcionais, mas também amigáveis (AAKER, 1997). Em contrapartida, não se pode analisar esse relacionamento como se a marca tivesse uma atuação passiva. Ao contrário, faz-se necessário considerar o que a marca pensa das pessoas, o que ela as diria se fosse uma pessoa (BLACKSTON, 1993). Assim, podese afirmar que a marca é um parceiro ativo no relacionamento (FOURNIER, 1998). Portanto, da mesma maneira como o comportamento humano pode alterar diretamente a percepção dos demais sobre sua personalidade, a personalidade de uma marca é afetada por seus comportamentos, influenciando diretamente no relacionamento entre a marca e o consumidor.

Neste sentido, e assim como ocorre com uma pessoa, as marcas podem assumir múltiplas personalidades, conforme o contexto e com seus diferentes papéis adotados, sendo, consequentemente, importante a atitude da marca percebida pelo consumidor. Com isto, entendemos que a personalidade da marca não é uma percepção a ser manipulada, mas constituída na interação com o cliente, em um processo de significação. Deve haver um Revista Eletrônica de Estratégia \& Negócios, Florianópolis, v.7, n.3, set./dez. 2014. 
alinhamento entre a marca, sua capacidade de propiciar autoexpressão aos seus consumidores e seu contexto de uso. A personalidade de marca é parte do significado cultural na construção de selfs sociais das pessoas (MCCRACKEN, 1986; 1989).

Assim, as marcas podem se tornar veículos de expressão de suas identidades para seus consumidores, pois pessoas utilizam bens e posses tanto para satisfazer necessidades funcionais, quanto para dar sentido e ordem às suas vidas (MÄLAR et al., 2011), fazendo com que a personalidade de marca possa influenciar os consumidores na escolha de produtos, por ser uma importante característica de socialização (SWAMINATHAN; STILLEY; AHLUWALIA, 2009).

O consumidor envolve-se com a personalidade de marca de forma a aprender a partir de suas próprias crenças e personalidade (PARK; ROEDDER JOHN, 2010). Por outro lado, as marcas proporcionam aos consumidores uma ideia de uma identidade singular ou de uma identidade comum (ESCALAS; BETTMAN, 2003).

Recorrendo a uma busca por trabalhos realizados sobre esse tema, percebemos que ele não tem sido explorado intensamente pela publicação nacional. O que encontramos do assunto tem se resumido às tentativas de entender determinadas escalas em contextos diferentes de sua aplicação original, alinhando-se a modelos teóricos mais abrangentes, ou mesmo como parte complementar a outros estudos. Dentro do conjunto de estudos levantados, as marcas brasileiras só foram estudadas mais recentemente.

A despeito desta afirmação encontramos, nos estudos de Muniz e Marchetti (2005), uma mensuração da personalidade de marca no Brasil, adaptando a escala de Aaker (1997) a seus propósitos, e encontrando resultados diferentes da personalidade destas marcas em comparação a pesquisas análogas realizados em outros países. Essa escala adaptada foi utilizada, posteriormente, em duas outras pesquisas. Na primeira, o intuito foi compreender a personalidade de uma marca de calçados brasileira (BICHUETI; BATTISTELA; GROHMANN, 2010); na segunda, utilizaram cidades como marcas a serem avaliadas por tal procedimento (PETROSKI; BAPTISTA; MARCHETTI, 2010). De certo modo, os objetivos assemelham-se ao intuito deste estudo - evidenciar a personalidade da marca - distinguindo-a, contudo, pelos procedimentos e paradigmas adotados.

De modo semelhante, Añaña e Nique (2009) recorreram a uma intercessão entre as escalas de valores de Rokeach $(1968,1973)$ e a escala de personalidade da marca de Aaker (1997) para avaliar a influência de subculturas regionais brasileiras na percepção e Revista Eletrônica de Estratégia \& Negócios, Florianópolis, v.7, n.3, set./dez. 2014. 
construção da imagem da marca Nike. Os resultados corroboraram sobre a influência da cultura na constituição da imagem da marca. A bricolagem entre as escalas, também foi utilizada por Leão, Souza Neto e Mello (2007) para analisar os valores humanos apontados às marcas, conforme percebidos por seus consumidores. Os resultados acrescentam, ao conhecimento, a área que parte do valor atribuído à marca é representativo a uma categoria. Também foi fundamentada em Mengarelli (2008) para entender como os adolescentes expressam suas subjetividades por meio do simbolismo atribuído a produtos e marcas. Neste caso, enfatizou-se a efemeridade de tais significados diante da inconsistência de representação de um perfil comportamental para este segmento.

Em outra adaptação de escalas, Pontes e Parente (2008), avaliam a personalidade de três marcas globais do segmento esportivo utilizando as escalas de Aaker (1997) e Kapferer (2003). Como resultado, encontram imagens semelhantes destas marcas em comparação a estudos estrangeiros.

Como mencionado anteriormente, também encontramos estudos orientados ao modo como a construção da personalidade de marca pode ser afetada por determinada estratégia de comunicação, apresentando, por resultado, um processo de aplicação intuitiva (FISHER, 2009), além do interesse pela personalidade da marca como parte necessária para o entendimento da constituição de estratégias de reposicionamento da marca (SERRALVO; FURRIER, 2008; DALFOVO; PEDROSO, 2008).

\section{PROCEDIMENTOS METODOLÓGICOS}

O presente trabalho caracteriza-se como um estudo qualitativo básico (MERRIAN, 1998), sob uma perspectiva interpretativista, em que a compreensão da realidade é construída por circunstâncias sociais, culturais e históricas; a função do pesquisador é a de coparticipante da edificação do conhecimento (DENZIN; LINCOLN, 2005; CRESWELL, 2010; PAIVA JR. et al., 2011) ${ }^{3}$. Este trabalho é um estudo semi-indutivo, adotando a teoria como lente ao invés de um construto e suas variáveis, mostrando-se, assim, mais flexível e

\footnotetext{
${ }^{3} \mathrm{Em}$ virtude desta escolha, o texto é escrito em primeira pessoa, conduta alinhada à dimensão axiológica deste paradigma, conforme Denzin e Lincoln (2005). Neste sentido, a opção pela primeira pessoa do plural deve-se não somente ao fato do artigo ter sido realizado por mais de um pesquisador, mas, sobretudo, por, nesta abordagem, entender-se que tanto os participantes da pesquisa como fontes de informação (entrevistados), quanto os autores das obras consultadas sejam coparticipantes da construção do conhecimento produzido. Revista Eletrônica de Estratégia \& Negócios, Florianópolis, v.7, n.3, set./dez. 2014.
} 
adaptável às respostas coletadas, o que permite identificar categorias empíricas (LEÃO; MELLO; VIEIRA, 2009).

Para a construção do corpus da pesquisa, recorremos a entrevistas em profundidade como método de coleta de dados escolhido. Tais entrevistas basearam-se em um tópico-guia (FLICK, 2009) composto por quatro questões abertas, em que uma serviu à função de filtro, permitindo avaliar o quão capaz fora o entrevistado para elaborar a resposta. As demais consistiam em questões direcionadas para o que marca significa para o consumidor, bem como sua relevância e o relacionamento entre as partes.

Os entrevistados foram escolhidos pelo método bola de neve, em que cada participante indica outras pessoas que possam ser entrevistadas, por serem clientes da marca estudada (BERNARD, 1994). Tivemos, ainda, o cuidado de verificar se os respondentes possuíam conhecimento sobre a marca, o que foi feito por meio da pergunta inicial. Ser cliente e demonstrar conhecimento sobre a marca foi o critério utilizado para selecionar o entrevistado, não havendo registro de aspectos demográficos, uma vez que estes não se aplicavam à análise proposta. O número de pessoas entrevistadas foi definido pelo princípio da saturação (BAUER; AARTS, 2002; THIRY-CHERQUES, 2009), o que ocorreu na nona entrevista, confirmado ao final de onze realizadas. As entrevistas foram realizadas na Região Metropolitana de Recife (RMR) em dezembro de 2011.

Os dados foram tratados através da análise do discurso funcional que, segundo Stiller (1998), assume a fala como discurso social. Para Mattos (2005) esta é uma perspectiva alinhada a uma análise sob uma ótica mais pragmática, o que significa que o uso que fazemos da linguagem é o que define o entendimento da sintaxe e da semântica das orações (WITTGENSTEIN, 2005). Assim, seguindo os passos sugeridos por Gill (2002), após a coleta das entrevistas, as falas foram decupadas por um profissional habilitado e validadas, em relação à entrevista gravada, por um bolsista de iniciação científica. Em seguida, dois dos autores alternadamente fizeram a mesma validação, o que se tornou bastante positivo, visto que foi uma oportunidade a mais para conhecerem melhor os textos, que foram lidos de maneira cética. Logo após, desconstruímos os textos para tentar encontrar elementos que pudessem fazer sentido, tanto em sua própria entrevista quanto no âmbito total da investigação. Fizemos a codificação dos textos, não considerando as categorias analíticas relativas à personalidade da marca e, após, passamos a fazer a análise em si, buscando encontrar a convergência e a variabilidade nos dados. Por fim, realizamos o teste de dados, Revista Eletrônica de Estratégia \& Negócios, Florianópolis, v.7, n.3, set./dez. 2014. 
utilizando critérios de validade e confiabilidade da pesquisa qualitativa (PAIVA JR; LEÃO; MELLO, 2011).

$\mathrm{Na}$ etapa seguinte, fizemos a análise das relações entre as categorias e, assim, construímos um mapa relacional entre os elementos. Todas as etapas foram desenvolvidas utilizando o procedimento de inter-coding reliability (MILES; HUBERMAN, 1994). Através deste método, cada um dos pesquisadores analisou as entrevistas, triangulando, em seguida, os resultados entre cada uma de suas próprias inferências. Ao final, uma última análise de validação sob o crivo do pesquisador responsável pela coordenação da pesquisa contribuiu para a definição dos resultados, atendendo aos critérios de validade e qualidade da pesquisa (PAIVA JR; LEÃO; MELLO, 2011).

Um software foi utilizado como apoio para a análise de dados. Contudo, não como analisadores em si, já que programas CAQDAS (Computer-Aided Qualitative Data Analysis Software) não fazem a análise sozinhos, servindo apenas de suporte (KELLE, 2002). O NVivo8 serviu para armazenar, organizar e cruzar as entrevistas. A codificação e a determinação das relações entre categorias foram realizadas sem a utilização de qualquer software, pois entendemos que tais inferências são funções dos pesquisadores, inclusive a construção do mapa, também foi feita pelos próprios pesquisadores, apesar de elaborado com auxílio do software utilizado.

A seguir, apesentamos os resultados de nossas análises. Com o intuito de seguir os critérios de qualidade da pesquisa qualitativa, procuramos evidenciá-los de forma densa e detalhada, objetivando tornar o trabalho compreensível, possibilitando sua transferibilidade (PAIVA JR.; LEÃO; MELLO, 2011).

\section{DESCRIÇÃO DOS RESULTADOS}

Nossa análise levou à identificação de oito categorias representativas das características da personalidade da marca Pague Menos. As mesmas são denominadas por meio de adjetivos, no intuito de serem elucidativas de que se referem a qualidades humanas, tendo em vista o conceito de personalidade de marca, conforme discutido na revisão de literatura. A Tabela 1 apresenta tais categorias e suas respectivas descrições. Por serem todas de caráter empírico, tais descrições apresentam, primeiramente, uma frase elucidativa de cada categoria em sentido conceitual, ainda que advinda da inferência 
empírica, seguida de um detalhamento sobre como cada uma delas foi identificada nos dados, sempre relacionadas a elementos (características) da marca.

Tabela 1 - Categorias e suas descrições

\begin{tabular}{|c|c|}
\hline Categoria & Descrição \\
\hline Acessível & $\begin{array}{l}\text { Remete à facilidade de acesso à marca. Em nossos achados, refere-se à distribuição } \\
\text { espacial dos pontos de venda e reconhecimento de preço justo, este relacionado à } \\
\text { forma de pagamento, promoções e descontos. }\end{array}$ \\
\hline Atenciosa & $\begin{array}{l}\text { Refere-se ao cuidado dispensado pela marca. Em nossos achados, está localizada nos } \\
\text { pontos de venda, que propiciam um ambiente agradável e seguro; e no atendimento } \\
\text { prestado pelos funcionários, que demonstram astúcia, respondem a questionamentos } \\
\text { e dúvidas, sendo prestativos em necessidades especiais; e calorosidade, estabelecendo } \\
\text { aproximação e intimidade. }\end{array}$ \\
\hline Diversificada & $\begin{array}{l}\text { Refere-se à variedade de opções da marca. No caso, diz respeito à oferta de produtos } \\
\text { além dos farmacêuticos. }\end{array}$ \\
\hline Magnânima & $\begin{array}{l}\text { Refere-se à generosidade da marca. Em nossos achados está presente nos programas } \\
\text { sociais que realiza, bem como na preocupação com seus funcionários, identificada no } \\
\text { tratamento diferenciado e na possibilidade de crescimento nas funções exercidas. }\end{array}$ \\
\hline Midiática & $\begin{array}{l}\text { Refere-se à projeção da marca. Remete à sua presença nos meios de comunicação de } \\
\text { massa, atuação em redes sociais e reconhecimento das ações promocionais. }\end{array}$ \\
\hline Prodigiosa & $\begin{array}{l}\text { Refere-se ao processo de êxito da marca. Em nossa pesquisa, remete à obtenção de } \\
\text { reconhecimento social derivado de seu êxito. }\end{array}$ \\
\hline Providente & $\begin{array}{l}\text { Refere-se à prontidão da marca. Em nossos achados, revela-se por não haver falta de } \\
\text { medicamentos. }\end{array}$ \\
\hline Relapsa & $\begin{array}{l}\text { Refere-se à displicência da marca. Em nossos achados, implica a falta de um } \\
\text { atendimento satisfatório. }\end{array}$ \\
\hline
\end{tabular}

Fonte: Elaboração dos autores.

A categoria Prodigiosa aparece como principal ponto de convergência de relações, apresentando ligações com todas as demais categorias, exceto com Relapsa.

O próximo passo foi analisar as relações existentes entre tais categorias. Debruçando-nos sobre as transcrições das entrevistas, mapeamos os pontos das falas dos entrevistados em que diferentes categorias estavam imbricadas em um mesmo sentido discursivo. Ao final de tal procedimento, pudemos elaborar um mapa de relações entre as categorias (Figura 1), o qual é elucidativo da dinâmica existente entre as mesmas.

Figura 1 - Mapa das relações entre as categorias 


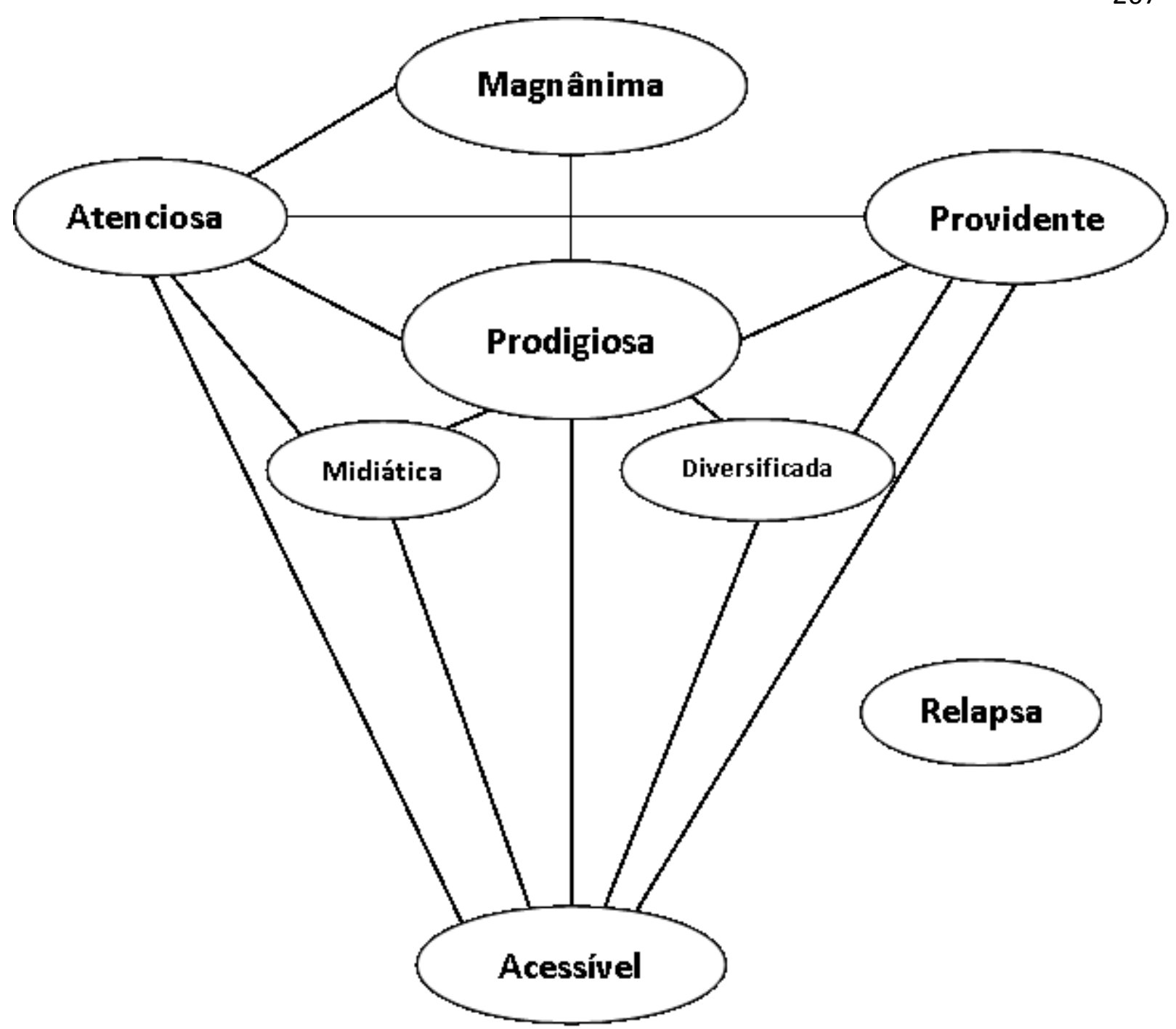

Fonte: elaborado pelos autores.

A partir de agora, passamos a elucidar cada uma destas relações, o que fazemos a partir das categorias com mais relações estabelecidas.

Começando por sua relação com Acessível, esta se encontra no fato de que a distribuição espacial dos pontos de venda e o reconhecimento da prática de preços justos contribuem para uma impressão de êxito da marca. Esta mesma percepção advém, também, do fato de não faltarem medicamentos nas lojas, o que estabelece a relação entre Prodigiosa e Providente, bem como de nestas se encontrar uma variedade de produtos que extrapola os farmacêuticos, o que caracteriza a relação com a categoria Diversificada. Para demonstrar tal lógica, consideremos o seguinte trecho da fala de um entrevistado:

Pelo menos aqui no Estado, a gente tem uma quantidade maior de farmácias da Pague Menos. A localização... Sempre tem uma farmácia próxima. Ela é umas das maiores que têm aqui. Os produtos são vendidos 
em outros lugares, mas lá você encontra uma variedade maior. [Além disto], não corre o risco de não ter o medicamento [...] que você procura.

Esta passagem revela como a acessibilidade à farmácia, propiciada pela sua rede de lojas, gera a percepção de que se trata de uma marca exitosa, evidenciando, portanto, a relação entre Acessível e Prodigiosa. Na sequência, a menção à variedade de produtos (Diversificada) e ao fato de nunca faltarem os medicamentos que se procura (Providente) evidenciam os aspectos relacionais apresentados.

Para elucidar outras duas relações da categoria prodigiosa, recorremos a outro trecho de fala de um consumidor:

Eu acho que ela [Pague Menos] já se firmou, a sua marca já está consolidada, todo mundo conhece. Eles investem muito em propaganda e eu acho interessante. Fazem promoções para manter essa ligação com os consumidores[...] Sempre em datas especiais, eles fazem alguma atividade[...].

Revela-se, aqui, o reconhecimento da consolidação da marca como advinda de seu investimento promocional, o que evidencia uma relação entre Prodigiosa e Midiática. Por outro lado, o consumidor parece entender que este movimento advém de seu intuito em manter relacionamento com seus clientes. Este exemplo revela a relação de Atenciosa com Prodigiosa, uma vez que se associa ao sucesso da marca sua atitude relacional, mas também evoca uma relação entre Atenciosa e Midiática por associar a atitude da marca a uma postura orientada por uma função de marketing.

A última relação de Prodigiosa é com Magnânima. Esta se refere a como a marca desenvolve ações de generosidade por meio de sua comunicação. O trecho abaixo ilustra este aspecto:

A empresa está um sucesso, nas redes sociais, tanto Twitter, como Facebook, tem muitos seguidores que sempre ficam sabendo das promoções, das dicas. Também eles fazem muitos trabalhos sociais, incentivando as pessoas a doarem brinquedos, ajudarem.

Entendemos, em meio aos argumentos de informações constantes por meio de redes sociais, ou mesmo campanhas de apelo social sendo percebidas pelo consumidor, como um gesto de generosidade da marca, como uma mãe que aconselha o seu filho sobre como fazer, ou mesmo sugerindo uma boa conduta.

Acessível é a categoria que aparece em seguida com maior número de relações. São cinco ao total. Além de Prodigiosa, ela se relaciona também com Diversificada, Providente, 
Atenciosa e Midiática. Um mesmo trecho de entrevista é elucidativo de duas destas relações:

Para mim, a Pague Menos é uma farmácia que você consegue encontrar, além de remédios, alguns produtos de higiene pessoal com preço mais em conta do que as outras farmácias no mercado[...] Pelo menos, nenhum dos produtos que eu procurei lá nunca esteve em falta[...]

A relação entre Acessível e Diversificada aparece aqui em meio a argumentação acerca da diversidade de outros produtos existentes além dos medicamentos, ademais do fácil acesso - neste caso, recorrente à precificação - aos produtos da marca. Por outro lado, a demonstração de confiança na disponibilidade desses produtos em loja aponta para relação com Providente. O consumidor reconhece maior possibilidade de acesso ao produto pelo preço, a oferta de produtos não farmacêuticos e o fato de não faltar medicamentos.

A relação entre Acessível e Atenciosa revela-se no entendimento de que a prática de preços justos seja uma demonstração de cuidado, por parte da Pague Menos, com seus clientes, como observamos no trecho a seguir, em que o entrevistado procura explicar sua noção de bom atendimento, locução adjetiva por ele apresentada como uma das qualidades da marca e que ilustra esta relação:

[A Pague Menos] significa, em primeiro momento, preço bom. Não digo preço baixo, mas um preço bom, que está dentro do que eu espero, da minha expectativa, [o que] significa um bom atendimento.

A relação entre Acessível e Midiática, por sua vez, é demonstrada em situações em que a massificação da marca, a aparição do próprio nome e pelas suas promoções, convencem de sua prática de preços baixos, conforme se percebe a partir do exemplo a seguir, em que o entrevistado procura explicar sobre o que a marca Pague Menos significa para ele:

Eu acho que tem um nome que chama a gente. O nome Pague Menos, para você comprar remédio, é atrativo, já que está se gastando tanto com medicação.

Entendemos, por meio desta passagem, como o nome da marca expressa um significado de fácil compreensão e que se alinha a uma necessidade econômica. Em sua resposta, o entrevistado reforça como o excesso de propaganda não o deixa esquecer o local que permitiria, a ele, servir-se com mais facilidade dos produtos demandados.

Também com cinco relações, encontramos a categoria Atenciosa. Além das relações antes mencionadas com Prodigiosa, Acessível e Midiática, identificamos sua interação com Providente e Magnânima. 
Quanto à relação com esta última, refere-se a como a generosidade demonstrada pela marca alinha-se ao cuidado com os clientes. No exemplo a seguir, isto fica evidente por meio da valorização da marca, ao demonstrar-se atenta às necessidades também do seu público interno, demonstrando-se generosa ao possibilitar o crescimento profissional destes.

[Conheço] um menino que trabalhava na Pague Menos e ele se mostrava bem empolgado com o trabalho, porque tinha a possibilidade de crescer na empresa, e acho que isso é que faz com que os funcionários se sintam mais motivados e atendam melhor.

Por fim, na relação entre Atenciosa e Providente, demonstra-se, por meio das falas dos entrevistados, que evidenciam o fato de sempre se encontrar os medicamentos que se procura (Providente) como consequência de cuidado com o cliente (Atenciosa), como se comprova na seguinte fala:

Eu acho que ela consegue o que quero [medicamento]. Geralmente, quando eu vou lá, o que eu quero, tem. E é acessível, tem em vários locais [...]; se torna presente quando eu quero.

Com três categorias cada, ainda temos Providente, Diversifica e Midiática. Todas se relacionam, tanto com Prodigiosa quanto com Acessível. Midiática relaciona-se, ainda, com Atenciosa. Por sua vez, Diversificada e Providente relacionam-se entre si. Por último, a categoria Magnânima relaciona-se com Prodigiosa e Atenciosa. Todas estas relações foram descritas acima.

Uma das categorias, todavia, não se relaciona com nenhuma outra. Relapsa é apresentada na percepção do consumidor como a ausência de atendimento satisfatório da marca. Seu isolamento dentre as outras categorias ocorre, provavelmente, devido ao fato de se tratar da única característica negativa identificada. A passagem a seguir a ilustra esta perspectiva:

Uma coisa que me chama muita atenção, na marca, é esse lance de não funcionar o telefone, que você liga e nunca atende, e quando atende a entrega é muito precária.

Embora possa, em uma abordagem tradicional, significar um desabono referente a uma falta de qualidade na prestação de um serviço, sob esta perspectiva, revela-se como a personalidade de marca não se institui apenas por meio da comunicação mercadológica da marca, mas por um processo holístico, dinâmico e complexo, onde um serviço ofertado para além da funcionalidade padrão confere significados relevantes na percepção do consumidor.

\section{CONSIDERAÇÕES FINAIS}


Provedora. Esta é a Pague Menos. Ou, pelo menos, é isto que este estudo exploratório sugere, ao retomarmos para o nosso problema de pesquisa. À exceção de Relapsa, as demais categorias demonstram-se fortemente interconectadas, sugerindo que possamos inferir a existência de uma característica ampla da personalidade da marca Pague Menos. Por outro lado, além de suas inter-relações, tais características sugerem, também, complementaridade conceitual. Assim, denominamos de Provedora tal característica ampla. No centro desta noção, identificamos as inter-relações entre providente, acessível e diversificada como demonstrativas da função mesma da marca. Tal aspecto, por sua vez, ocorre de uma dada maneira (Atenciosa), e orientada por um valor relevante (Magnânima). Com isto, a marca obtém seu êxito, reforçada por sua presença na mídia.

Assim, a partir das diferentes características de sua personalidade, nossa análise propiciou localizar sua identidade singular (ESCALAS; BETTMAN, 2003), ficando evidente ser este o laço fundamental da relação entre esta e seus clientes (FOURNIER, 1998).

Por meio da marca escolhida, percebemos como, no processo relacional, a personalidade da marca dificilmente se restringiria aos significados atribuídos pelos gestores da marca, compartilhados por meio da função de comunicação de marketing. A marca manifesta-se a partir de diferentes elementos para os consumidores, de modo dinâmico. Neste sentido, podemos inferir que os consumidores personificam a marca de modo particular, o que possibilita existirem diferentes personalidades de uma mesma marca, conforme a experiência do seu consumidor e do grupo ao qual faz parte. Isto sugere maior ênfase no aspecto relacional (amigável) da marca, em comparação com o funcional (AAKER, 1997). Destes aspectos derivamos, também, o entendimento da relevância da marca em uma dimensão simbólica (MÄLAR et al., 2011; SWAMINATHAN; STILLEY; AHLUWALIA, 2009).

Tal perspectiva reporta a relevância para os gestores e profissionais de marketing, em debruçarem-se sobre os significados construídos sob a ótica dos diferentes grupos de consumidores, na busca por outros, quiçá melhores, caminhos de ação para alcance dos seus objetivos, buscando um alinhamento entre sua estratégia de posicionamento e a visão dos consumidores. Por outro lado, o resultado proporciona outra forma de se pensar a respeito das marcas. Ainda que escalas consagradas do construto teórico em pauta sejam úteis para a avalição de marcas, procedimentos metodológicos mais abertos podem apontar para características mais específicas de cada marca. Esta etapa exploratória pode ser base para um estudo descritivo mais aprofundado, que se beneficie de escalas validades como Revista Eletrônica de Estratégia \& Negócios, Florianópolis, v.7, n.3, set./dez. 2014. 
referência sem, no entanto, assumir que suas variáveis sejam atribuíveis a qualquer situação.

Evidentemente, a presente pesquisa limitou-se a conhecer a marca Pague Menos por meio dos consumidores de uma única Região Metropolitana do país e, por outro lado, seu caráter exploratório restringe o alcance dos achados. Todavia, é justamente esta característica (pesquisa exploratória) que justifica as escolhas feitas. Como pudemos argumentar, faz-se premente a ampliação de estudos que sejam realizados no contexto brasileiro, de forma mais indutiva, de maneira a identificar características de personalidade de marca que, talvez, sejam particulares de nossa cultura. Sendo assim, que mais pesquisas exploratórias sobre a personalidade de marcas brasileiras, a exemplo do que ora apresentamos, possam contribuir para uma massa crítica que venha a culminar com um construto adaptado ao contexto nacional.

\section{REFERÊNCIAS}

AAKER, D. A. Criando e administrando marcas de sucesso. São Paulo: Futura, 1996.

AAKER, D. A. Marcas: brand equity: gerenciando o valor da marca. São Paulo: Negócio.

AAKER, J. L. Dimensions of brand personality. Journal of Marketing Research, v.34, n.3, p.347-356, 1997.

AÑAÑA, E. S.; NIQUE, W. M. O valor dos valores: avaliação de uma marca global por meio dos diversos brasis culturais. Revista de Administração Mackenzie, v. 10, n. 3, p. 153-181, 2009.

AZOULAY, A.; KAPFERER, J. N. Do brand personality scales really measure brand personality? Journal of Brand Management, v.11, n.2, p.143-155, 2003.

BAUER, M.; AARTS, B. A construção do corpus: um princípio para a coleta de dados qualitativos. In: BAUER, M.; GASKEL, G. (Eds.). Pesquisa qualitativa com texto, imagem e som: um manual prático. Petrópolis: Vozes, 2002.

BERGER, P. L.; LUCKMANN, T. A construção social da realidade. 31ª ed. Petrópolis: Vozes, 2009.

BERNARD, H. R. Research methods in anthropology: qualitative and quantitative approaches. 2nd ed. London: Sage, 1994.

BICHUETI, R. S.; BATTISTELA, L. F.; GROHMANN, M. Z. Personalidade de marca: Um estudo da percepção dos consumidores da Eny Comércio de Calçados. In: XIII SEMEAD. Anais... São Paulo, 2010. 
BLACKSTON, M. Beyond brand personality: Building brand relationships. In: AAKER, D.; BIEL, A. Brand equity and advertising. Ed. Hillsdale: Lawrence Erlbaum Associates, 1993, p.113-34.

BROWN, S. Marketing as multiplex: screening postmodernism. European Journal of Marketing, v. 28, n. 8/9, p. 27-51, 1994.

COVA, B. Community and consumption: towards a definition of the "linking value" of product or services. European Journal of Marketing, v.31, n. 3/4, p.297-316, 1997.

CRESWELL, J. W. Projeto de pesquisa: métodos qualitativos, quantitativos e misto. 3 a ed. Porto Alegre: Artemed, 2010.

DALFOVO, M. S.; PEDROSO, A. A percepção dos clientes multimarcas referente ao novo posicionamento da marca Hering. Revista Interdisciplinar Científica Aplicada, v.2, n.2, p.0122, 2008.

DENZIN, N.; LINCOLN, Y. Paradigmatic controversies, contradictions, and emerging confluences. In: DENZIN, N.; LINCOLN, Y. (Eds.). The Sage Handbook of qualitative research. 3. ed. Thousand Oaks: Sage Publications, 2005.

ESCALAS, J. E.; BETTMAN, J. You are what they eat: the influence of reference groups in consumer's connections to brands. Journal of Consumer Psychology, v.13, n.3, p.339-348, 2003.

FARIA, A. Crítica e cultura em marketing: repensando a disciplina. Cadernos EBAPE, v. 4, n.3, p. 01-16. 2006.

FISCHER, J. K. Comunicação integrada de marketing como estratégia de construção da personalidade de marca: A análise qualitativa de uma empresa têxtil. In: XXXIII Encontro da ANPAD. Anais... São Paulo, 2009.

FLICK, U. Introdução à pesquisa qualitativa. 3.ed. Porto Alegre: Bookman/Artmed, 2009. $405 p$.

FOURNIER, S. Consumers and their brands: Developing relationship theory in consumer research. Journal of Consumer Research, v. 24, n.4, mar., p.343-353, 1998.

GILL, R. Análise de discurso. In: BAUER, M.; GASKEL, G. (Eds.). Pesquisa qualitativa com texto, imagem e som: um manual prático. Petrópolis: Vozes, 2002, p. 244-270.

GOBÉ, M. A emoção das marcas. São Paulo: Negócio, 2002.

GROHMANN, B. Gender dimensions of brand personality. Journal of Marketing Research, v.46, n.1, p.105-19, 2009. 
GUERRERO, N. E. C. Percepción del valor de la marca en restaurantes a traves de tres modelos de Evaluación. Revista de Administração da UNIMEP, v. 6, n.2, mai./ago. p. 1-25, 2008.

HOLT, D. B. (2002). Why do brands cause trouble? A dialectical theory of consumer culture and branding. Journal of Consumer Research, v.29, n.1, p.70-90, 2002.

KAPFERER, J-N I. As marcas: capital da empresa, Porto Alegre: Bookman, 1998.

KELLE, U. Análise com auxílio de computador: codificação e indexação. In: BAUER, M.; GASKEL, G. (Eds.). Pesquisa qualitativa com texto, imagem e som: um manual prático. Petrópolis: Vozes, 2002, cap. 16, p. 393-415.

KELLER, K. L. How to navigate the future of brand management. Marketing Management, v.20, n.2, p.36-46, 2011.

KIM, J.; BAEK, T. H.; MARTIN, H. J. Dimensions of news media brand personality. Journalism \& Mass Communication Quarterly, v.87, n.1, p,117-34, 2010.

LEÃO, A. L. M. S.; SOUZA NETO, A. F.; MELLO, S. C. B. Compreendendo os valores das marcas: aplicação da lista de valores em diferentes indústrias. Revista de Administração Contemporânea, v.11, n.2, p. 27-48, 2007.

LEÃO, A. L. M. S.; MELLO, S. B. C.; VIEIRA, R. S. G. O papel da teoria no método de pesquisa em Administração. Revista Organizações em Contexto, v.5(10), p.1-16, 2009.

LEÃO, A. L. M. S.; MELLO, S. B. C.; FREITAS, G. Usos das Marcas para o Alinhamento do "Eu" (footing) em Interações Sociais. Revista Brasileira de Gestão de Negócios, v.13, n. 38, pp. 61-79, 2011.

LEE, M. J. Consumer culture reborn: The cultural politics of consumption. London: Routledge, 1993.

MADRIGAL R.; BOUSH, D. Social responsibility as a unique dimension of brand personality and consumers' willingness to reward. Psychology \& Marketing, v.25, n.6, p.538-64, 2008.

MALÄR, L.; KROHMER, H.; HOYER, W.; NYFFENEGGER, B. Emotional brand attachment and brand personality: The relative importance of the actual and the ideal self. Journal of Marketing, v.75, n.4, p.35-52, 2011.

MATTOS, P. L. A entrevista não-estruturada como forma de conversação: razões e sugestões para sua análise. Revista de Administração Pública, Rio de Janeiro, v.39, n.4, p.823-47, 2005.

MCCRACKEN, G. Culture and consumption: A theoretical account of the structure and movement of the cultural meaning of consumer goods. Journal of Consumer Research, v.13, n1, p.71-84, 1986. 
MCCRACKEN, G. Who is the celebrity endorser? Cultural foundations of the endorsement process. Journal of Consumer Research, v.16, n.3, p.310-21, 1989.

MELLO, S. C. B. de. Comentários: o que é o conhecimento em marketing no Brasil, afinal?. Revista de Administração Contemporânea, v.10, n.2, p. 203-212. 2006.

MENGARELLI, A. P. C. Dimensões da personalidade de marca: Construção e validação de uma escala adaptada aos consumidores adolescentes. In: XXXII Encontro da ANPAD. Anais... Rio de Janeiro, 2008.

MERRIAN, S. Qualitative research and case study applications in education. San Francisco: Jossey-Bass, 1998.

MILES, M.; HUBERMAN, M. Qualitative data analysis: an expanded source book. 2.ed. London: Sage Publications, 1994.

MISOCZKY, M. C.; AMANTINO-DE-ANDRADE, J. Uma crítica à crítica domesticada nos estudos organizacionais. Revista de Administração Contemporânea, v. 9, n. 1, p. 192-210, 2005.

MUNIZ, K. M.; MARCHETTI, R. Dimensões da personalidade de marca: Análise da adequação da escala de Aaker (1997) ao contexto brasileiro. In: XXIX Encontro da ANPAD. Anais... Brasília, 2005.

PAIVA JR., F. G.; LEÃO, A. L. M. S.; MELLO, S. C. B. Validade e confiabilidade na pesquisa qualitativa em Administração. Revista de Ciências da Administração, v.13, n.31, p.190-209, 2011.

PALMATIER, R.; JARVIS, C. B.; BECHKOFF, J. R.; KARDES, F. The role of customer gratitude in relationship marketing. Journal of Marketing, v.73, n.5, p.1-18, 2011.

PARÍS, J. A. El significado del producto y su impacto en la marca. Revista de Administração da UNIMEP, v.9, n.3, set./dez. p. 24-39, 2011.

PARK, J. K.; ROEDDER JOHN, D. Got to get you into my life: Do brand personalities rub off on consumers? Journal of Consumer Research, v.37, n.4, p.655-69, 2010.

PATSIOURA, F.; MALAMA, E. L.; VLACHOPOULOU, M. A relationship marketing model for brand advertising websites: An analysis of consumers' perceptions. International Journal of Management, v.28, n.4, p.72-91, 2011.

PETROSKI, T. A. B.; BAPTISTA, P. P.; MARCHETTI, R. Z. Cidades como marcas: Análise da aplicabilidade do conceito de personalidade de marcas ao contexto de cidades. In: XXXIV Encontro da ANPAD. Anais... Rio de Janeiro, 2010.

PONTES, N. G.; PARENTE, J. G. Personalidade de marca: Como se mede? In: XXXII Encontro da ANPAD. Anais... Rio de Janeiro, 2008. 
RIES, A. Posicionamento: a batalha por sua mente. 20ạ ed. São Paulo: Makron Books, 2002.

ROCHA, T.; FUHRER, C. F.; KATAYAMA, N. H.; CHERUBINI, T. K. A construção da lealdade e imagem de marca no setor de telefonia móvel. Revista de Administração da UNIMEP, v.8, n.2, mai./ ago. p. 180-199, 2010.

ROKEACH, M. Beliefs, attitudes and values: a theory of organization and change. Hoboken: Jossey-Bass, 1968.

ROKEACH, M. The nature of human values. New York: The Free Press, 1973.

SEMPRINI, A. A marca pós-moderna: poder e fragilidade da marca na sociedade contemporânea. São Paulo: Estação das Letras, 2006.

SERRALVO, F. A.; FURRIER, M. T. reposicionamento de marcas: estudo de casos brasileiros. Revista Brasileira de Gestão e Negócios. v.10, n.26, p. 1-16, 2008.

SONNIER, G.; AINSLE, A. Estimating the value of brand-image associations: The role of general and specific brand image. Journal of Marketing Research, v.48, n.3, p.518-31, 2011.

STILLER, G. Analyzing everyday texts: discourse, rhetoric, and social perspectives. Thousand Oaks: Sage Publications, 1998.

SUNG, Y.; CHOI, S. M. "I won't leave you although you disappoint me": The interplay between satisfaction, investment, and alternatives in determining consumer-brand relationship commitment. Psychology \& Marketing, v.27, n.11, p.1050-1073, 2010.

SWAMINATHAN, V.; PAGE, K.; GÜRHAN-CANLI, Z. "My" brand or "our" brand: The effects of brand relationship dimensions and self-construal on brand evaluations. Journal of Consumer Research, v.34, n.2, p.248-259, 2007.

SWAMINATHAN, V.; STILLEY, K.; AHLUWALIA, R. When brand personality matters: The moderating role of attachment styles. Journal of Consumer Research, v.35, n.6, p.985-1002, 2009.

THIRY-CHERQUES, H. R. Saturação em pesquisa qualitativa: estimativa empírica de dimensionamento. Revista PMKT. n.3, p.20-27, 2009.

VIEIRA, R. S. G.; DIAS, C. M.; FILHO, J. R.; NETO, M. A. O conhecimento de marketing sob os olhos da teoria crítica. In: XXVI Encontro da ANPAD. Anais... Salvador: 2002.

VIEIRA, W. Análise do posicionamento da marca Natura no segmento de cosméticos antisinais: aplicação empírica no mercado curitibano. Revista de Administração da UNIMEP, v. 4, n. 1, jan./abr. p. 95-118, 2006

WITTGENSTEIN, L. Investigações filosóficas. 3. ed. Petrópolis: Vozes, 2005. 